\section{Teriparatide in the Treatment of a Loose Hip Prosthesis}

\section{To the Editor:}

The complexity of surgical and medical problems associated with reimplantation of a loose hip prosthesis does not always render this procedure acceptable. In addition, certain drugs may enhance the quality of bone around the prosthesis ${ }^{1,2}$. We treated a patient with teriparatide following loosening of his hip prosthesis, which was implanted for the second time; further surgery was no longer an option.

The patient had osteoarthritis and had an uncemented prosthesis when he was 56 years of age; by the age of 61 years he required a reimplant, as a result of aseptic loosening. At the age of 74 years, he began to develop increasing pain and progressive loss of power. He had a history of dilated cardiomyopathy, and in view of this a surgical solution was ruled out. By the age of 77 years, he was treated with clodronate (100 mg intramuscularly weekly) and oral calcium (1.5 g daily) for 1 year. At age 78 , radiographic imaging showed extensive loosening of the bone around the cup and a marked reduction in cortical thickness. Although he was already using a cane, he was advised to use 2 canes to allow partial weight-bearing. He was subsequently prescribed teriparatide $(20 \mu \mathrm{g}$ daily for 7 months). Prior to this treatment (Time 0 ) he underwent the following investigations: (1) Conventional radiography; computed tomography (CT) of the pelvis and left hip with assessment of bone mineral density (BMD) in the sacral promontory (S1); analysis of the bone region surrounding the prosthetic cup; analysis of the thickness of the femoral cortex in the calcar region and immediately below the calcar; and analysis of the cortex in the region adjacent to the tip of the prosthesis. (2) Clinical test: the Western Ontario and McMaster Universities Osteoarthritis Index (WOMAC) ${ }^{3}$, used to measure pain, stiffness, and function in activities of daily living (ADL). (3) Laboratory tests: calcium, phosphorus, total alkaline phosphatase (ALP), bone ALP, osteocalcin, parathyroid hormone, collagen cross-linked C-telopeptide-I.

Four months after the start of the study (Time 1) the clinical and laboratory tests were repeated; 8 months later (Time 2), all tests were repeated. On followup at Time 1, the WOMAC showed a reduction in pain walking on flat ground and less dependence in ADL (Table 1). The stiffness had not changed. Laboratory tests (Table 2) showed activation of the markers referable to osteoblasts and inhibition of bone reabsorption.
On followup at Time 2, radiography showed improvement of the bone stock in the calcar region (Figure 1). The CT (Table 3) showed the following results: (1) at $\mathrm{S} 1$ a change in BMD of $+77.7 \%$ between $\mathrm{T} 0$ and $\mathrm{T} 2$; (2) in the region corresponding to the prosthetic cup, a slight increase of bone of the quadrilateral lamina $(0.7 \mathrm{~mm})$; (3) in the region of the femoral calcar and immediately beneath the calcar, the cortex appeared discontinuous at $\mathrm{T} 0$ with numerous areas of interruption; at $\mathrm{T} 2$ the $\mathrm{CT}$ showed reconstitution of the cortex (Figure 2): in the 2 areas where there had previously been an interruption of the cortical outline, the thickness was $2 \mathrm{~mm}$ and 3.3 $\mathrm{mm}$, respectively; (4) at the tip of the stem, the cortex at T0 appeared intact but markedly osteopenic; at T2 the thickness was increased by $1.5 \mathrm{~mm}$.

The WOMAC showed further improvement: walking on flat ground was no longer a source of pain and the patient was able to carry out ADL. In addition, joint stiffness had improved slightly. The laboratory tests showed a drop of resorptive activity at $\mathrm{T} 2$ compared with $\mathrm{T} 1$.

Our clinical case shows how it is possible to manage a loosened hip prosthesis with pharmacological therapy. The analgesic action of teriparatide has been described ${ }^{4,5}$; however, the level of independence achieved was similar to that often obtained after repeated implants.

CT scans confirmed the possibility of increasing BMD of both cancellous and cortical bone with teriparatide ${ }^{6,7}$. The increase in the cancellous bone achieved in just 8 months was striking. However, contrasting findings were observed at the acetabular level, where significant changes in the bone tissue were not recorded. In fact, at T0 the area surrounding the prosthetic cup was the site of extensive loosening and this may have altered the microenvironment required for effective osteogenesis. It is plausible that the use of a stabilizing support for the hip might improve the result. At the femoral diaphysis, however, we found reconstitution of cortical continuity at all levels that were examined; the patient's greater stability and increased independence are probably due to this improvement. Finally, the laboratory results emphasized the metabolic action of the drug, according to a well known sequence of events ${ }^{8}$. We visited the patient several times following his treatment; the last time, 2 years after T0, the clinical picture was the same, the patient did not feel pain, and the level of autonomy was unchanged. The use of teriparatide for treatment of loosened and inoperable prostheses therefore seems rational $1^{9,10,11}$ and is a valid alternative to surgery; certainly, further clinical studies are advisable to complement these findings.

Table 1. WOMAC test results show changes in scores of absolute data (percentage differences) at baseline (T0), after 4 months (T1), and after 8 months of treatment (T2).

\begin{tabular}{lcccc}
\hline WOMAC Test & Time 0 & Time 1 & Time 2 & Difference T2 > T0, \% \\
\hline Pain & 15 & $10(-33.33)$ & $8(-20)$ & -46.66 \\
Stiffness & 4 & $4(0)$ & $3(-25)$ & -25 \\
Function & 65 & $59(-6.1)$ & $55(-6.77)$ & -15.3 \\
Total & 84 & $73(-13.09)$ & $66(-9.58)$ & -21.42 \\
\hline
\end{tabular}

Table 2. Markers of bone metabolism show changes in the main indices of bone metabolism: absolute (percentage differences) at baseline (T0), after 4 months (T1), and after 8 months (T2).

\begin{tabular}{lccccc}
\hline Test & Unit & Time 0 & Time 1 & Time 2 & Difference T2 vs T0, \% \\
\hline Calcium & $\mathrm{mg} / 100 \mathrm{ml}$ & 9.3 & $9.5(+2.15)$ & $9.5(0)$ & +2.15 \\
Phosphorus & $\mathrm{mg} / 100 \mathrm{ml}$ & 3.3 & $3.1(-6.06)$ & $3.2(+3.22)$ & -3.03 \\
Total ALP & $\mathrm{U} / \mathrm{I}$ & 86 & $108(+25.58)$ & $111(+2.77)$ & +29.06 \\
Bone ALP & $\mu \mathrm{g} / \mathrm{l}$ & 12 & $20(+66.66)$ & $13.3(-33.5)$ & +10.83 \\
Osteocalcin & $\mathrm{ng} / \mathrm{ml}$ & 11.9 & $15.7(+31.93)$ & $12.5(-20.38)$ & +5.04 \\
PTH & $\mathrm{pg} / \mathrm{ml}$ & 54.1 & $43.00(-20.51)$ & $31.9(-25.81)$ & -41.03 \\
CTX-I & $\mathrm{pg} / \mathrm{ml}$ & 164 & $158(-3.65)$ & $152(-2.53)$ & -7.31 \\
\hline
\end{tabular}

ALP: alkaline phosphatase; PTH: parathyroid hormones; CTX-I: collagen cross-linked C-telopeptide-I. 


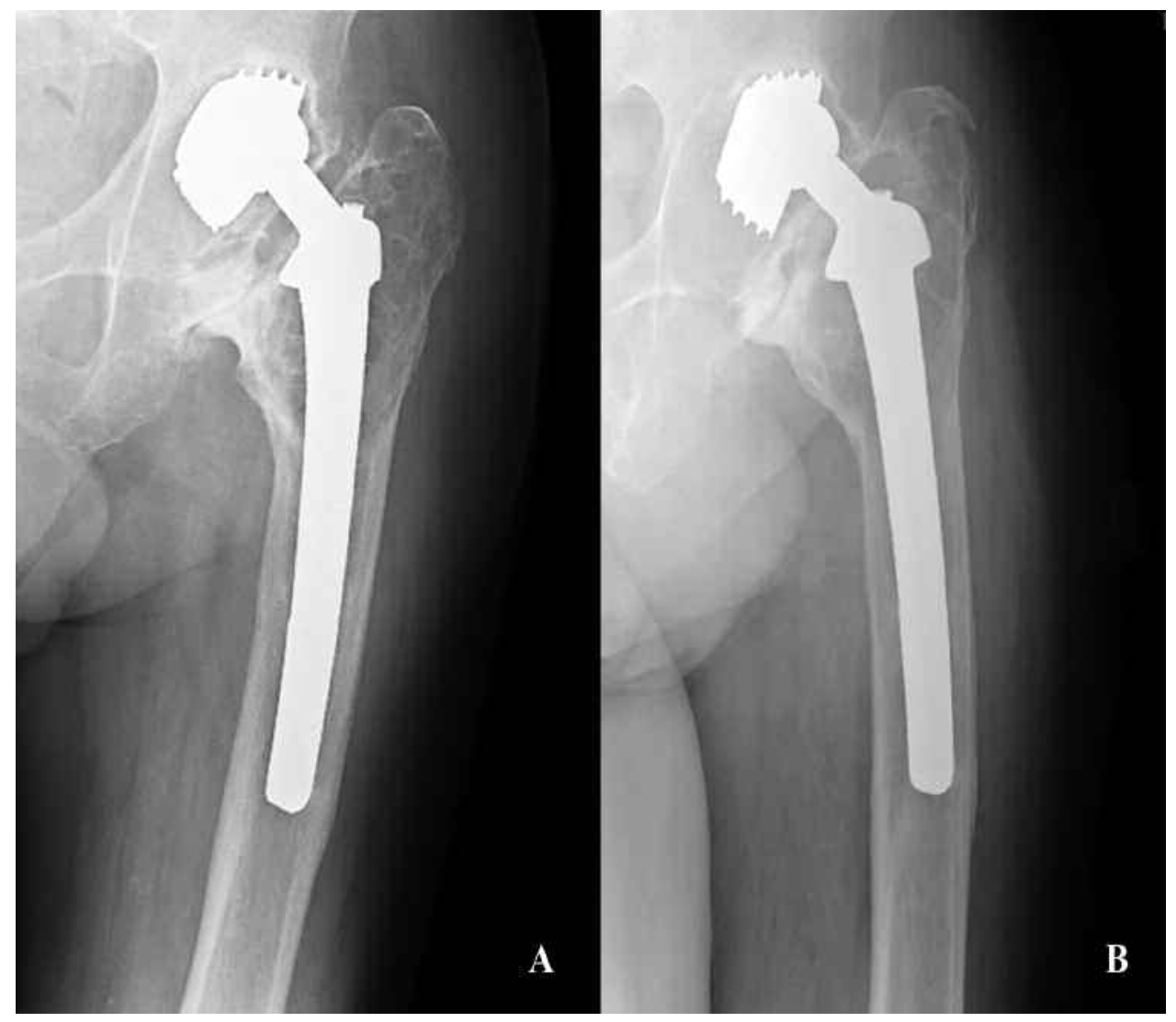

Figure 1. Conventional radiographs of calcar region of the femur show marked improvement of periprosthetic bone from baseline (A) and after 8 months of therapy (B).

Table 3. CT results: assessment of bone mineral density (BMD) in Hounsfield units (HU) at the sacral promontory (S1) in an area of $566 \mathrm{~mm}^{2}$. Measurement of periprosthetic bone thickness (in mm) at the apex of the acetabular convexity, the calcar, below the calcar, and at the apex of the stem; absolute and percentage differences between baseline (T0) and after 8 months (T2).

\begin{tabular}{lcccc}
\hline CT Result & Unit & Time 0 & Time 2 & Difference T2 vs T0 \\
\hline S1 BMD & HU & 87.15 & 154.32 & $+77.70 \%$ \\
Quadrilateral lamina acetabulum distance & $\mathrm{mm}$ & 17.90 & 18.60 & $+3.91 \%$ \\
Thickness of femoral cortex at calcar & $\mathrm{mm}$ & 0 & 2 & $2.00 \mathrm{~mm}$ \\
Thickness of femoral cortex below calcar & $\mathrm{mm}$ & 0 & 3.3 & $3.30 \mathrm{~mm}$ \\
Thickness of cortex at tip of prosthesis & $\mathrm{mm}$ & 9.10 & 11.10 & $+21.97 \%$ \\
& & & \\
\hline
\end{tabular}

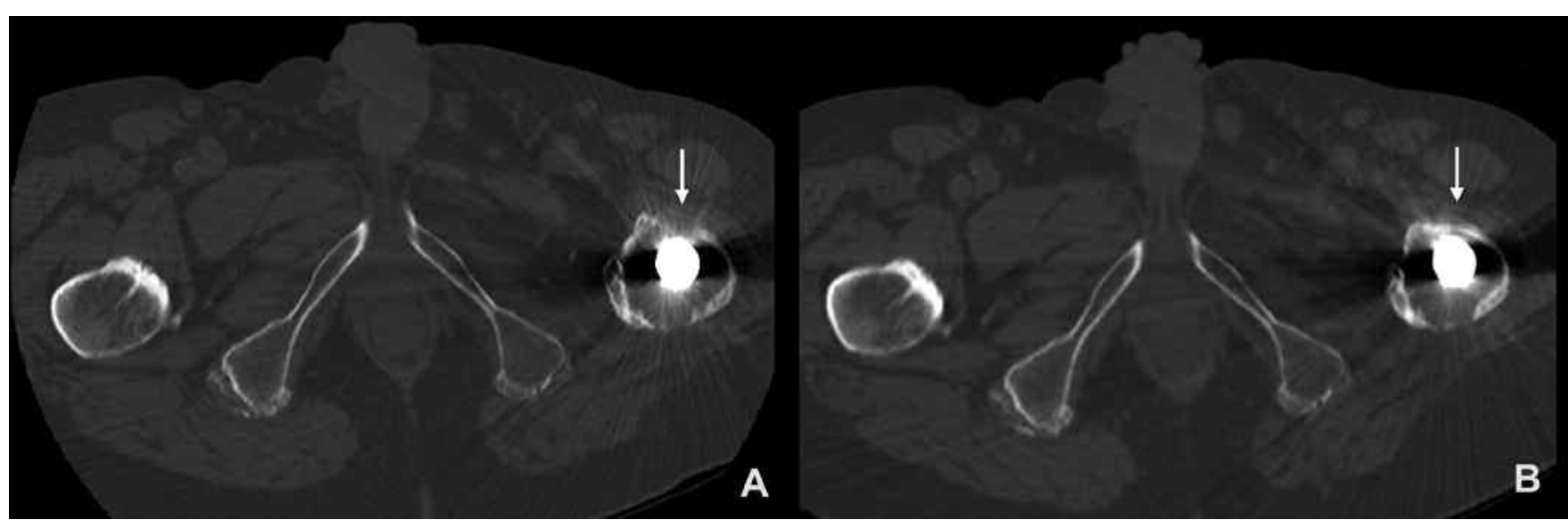

Figure 2. Computed tomography of periprosthetic tissue at the level of the femoral calcar at baseline (A) and after 8 months of therapy (B). A. Discontinuity in the anterior region of the femoral diaphysis at T0. B. Reconstitution of the diaphysis after 8 months, at T2. 
ALESSANDRO ZATI, MD, Medicina Fisica e Riabilitazione, Istituto Ortopedico Rizzoli, Bologna; DANIELE SARTI, MD, Medicina Fisica e Riabilitazione, Ospedale SS. Salvatore, San Giovanni in Persiceto, Bologna; MARIA CRISTINA MALAGUTI, MD, Radiologia, Istituto Ortopedico Rizzoli, Bologna; LOREDANA PRATELLI, MD, Patologia Clinica, Istituto Ortopedico Rizzoli, Bologna, Italy. Address correspondence to Dr. D. Sarti, Via Mario Conti 53, San Lazzaro di Savena, Bologna, 40068, Italy. E-mail: danielesarti1978@gmail.com

\section{REFERENCES}

1. Tsiridis E, Gamie Z, Conaghan PG, Giannodius PV. Biological options to enhance periprosthetic bone mass. Injury 2007; 38:704-13.

2. Foster SA, Foley KA, Meadows ES, Johnston JA, Wang S, Pohl GM, et al. Characteristics of patients initiating teriparatide for the treatment of osteoporosis. Osteoporos Int 2008;19:373-7.

3. Bellamy N, Buchanan WW, Goldsmith CH, Campbell J, Stitt LW. Validation study of WOMAC: a health status instrument for measuring clinically important patient relevant outcomes to antirheumatic drug therapy in patients with osteoarthritis of the hip or knee. J Rheumatol 1988;15:1833-40.

4. Miller PD, Shergy WJ, Body JJ, Chen P, Rohe, ME, Krege JH. Longterm reduction of back pain risk in women with osteoporosis treated with teriparatide compared with alendronate. J Rheumatol 2005;32:1556-62.
5. Nevitt MC, Chen P, Kiel DP, Reginster JY, Dore RK, Zanchetta JR, et al. Reduction in the risk of developing back pain persists at least 30 months after discontinuation of teriparatide treatment: a meta-analysis. Osteoporos Int 2006;17:1630-7.

6. Neer RM, Arnaud CD, Zanchetta JR, Prince R, Gaich GA, Reginster JY, et al. Effect of parathyroid hormone (1-34) on fractures and bone mineral density in postmenopausal women with osteoporosis. N Engl J Med 2001;344:1434-41.

7. Jiang Y, Zhao J, Mitlak BH, Wang O, Genant HK, Eriksen EF. Recombinant human parathyroid hormone (1-34) [teriparatide] improves both cortical and cancellous bone structure. J Bone Miner Res 2003;18:1932-41.

8. Girotra M, Rubin MR, Bilezikian JP. The use of parathyroid hormone in the treatment of osteoporosis. Rev Endocr Metab Disord 2006;7:113-21.

9. Iolascon G, Gimigliano F, Resmini G. Teriparatide and orthopedic surgery. Aging Clin Exp Res 2007;19:22-5.

10. Brunnemann CE, Reisinger EC, Ganzer D, Schober HC. Parathyroid hormone injection to counteract delayed bone fractures. Dtsch Med Wochenschr 2010;135:1538-41.

11. Johansson HR, Skripitz R, Aspenberg P. Bisphosphonates can block the deterioration in implant fixation after withdrawal of intermittent doses of parathyroid hormone. J Bone Joint Surg Br 2008;90:400-4.

J Rheumatol 2011;38:4; doi:10.3899/jrheum.100980 